\title{
Procalcitonin as a biomarker for severe Plasmodium falciparum disease: a critical appraisal of a semi-quantitative point-of-care test in a cohort of travellers with imported malaria Dennis A Hesselink ${ }^{1}$, Jan-Steven Burgerhart ${ }^{2}$, Hanna Bosmans-Timmerarends ${ }^{2}$, Pieter Petit ${ }^{3}$ and Perry JJ van Genderen*2
}

Address: ${ }^{1}$ Department of Internal Medicine, Erasmus MC, Rotterdam, the Netherlands, ${ }^{2}$ Department of Internal Medicine, Harbour Hospital and Institute for Tropical Diseases, Haringvliet 2, 3011 TD Rotterdam, the Netherlands and ${ }^{3}$ Department of Microbiology, Vlietland Hospital, Schiedam, the Netherlands

Email: Dennis A Hesselink - d.a.hesselink@erasmusmc.nl; Jan-Steven Burgerhart - j.s.burgerhart@hotmail.com; Hanna BosmansTimmerarends - hanna@christelijkpodium.nl; Pieter Petit - ppetit@ssvz.nl; Perry JJ van Genderen* - p.van.genderen@ havenziekenhuis.nl

* Corresponding author

Published: I September 2009

Malaria Journal 2009, 8:206 doi:10.1186/1475-2875-8-206
Received: 9 February 2009

Accepted: I September 2009

This article is available from: http://www.malariajournal.com/content/8/I/206

() 2009 Hesselink et al; licensee BioMed Central Ltd.

This is an Open Access article distributed under the terms of the Creative Commons Attribution License (http://creativecommons.org/licenses/by/2.0), which permits unrestricted use, distribution, and reproduction in any medium, provided the original work is properly cited.

\begin{abstract}
Background: Imported malaria occurs as a relatively rare event in developed countries. As a consequence, most clinicians have little experience in making clinical assessments of disease severity and decisions regarding the need for parenteral therapy or high-level monitoring. In this study, the diagnostic accuracy of procalcitonin (PCT) for severe Plasmodium falciparum disease was assessed in a cohort of 100 consecutive travellers with various species of imported malaria.
\end{abstract}

Methods and results: In all patients, PCT was measured on admission with a semi-quantitative 'point-of-care' test. Patients with severe P. falciparum malaria had significantly higher median PCT levels on admission as compared with patients with uncomplicated $P$. falciparum disease. In addition, PCT levels in patients with non-falciparum malaria were also higher compared with patients with non-severe falciparum malaria but lower compared with severe $P$. falciparum malaria. At a cut-off point of $10 \mathrm{ng} / \mathrm{mL}$, PCT had a sensitivity of 0,67 and a specificity of 0,94 for severe falciparum disease. However, at lower cut-off points the specificity and positive predictive value were rather poor although the sensitivity and negative predictive value remained high.

Discussion: Potential drawbacks in the interpretation of elevated PCT levels on admission may be caused by infections with non-falciparum species and by concomitant bacterial infections.

Conclusion: Semi-quantitative determination of PCT on admission is of limited use in the initial clinical assessment of disease severity in travellers with imported malaria, especially in settings with limited experience with the treatment of malaria.

\section{Background}

Imported malaria occurs as a relatively rare event in developed countries. As a consequence, most clinicians have little experience in making clinical assessments of disease severity and decisions regarding the need for parenteral therapy or high-level monitoring. In addition, obtaining a correct diagnosis of malaria may be troublesome in centres where laboratory staff are less skilled in preparing 
malaria thick and thin smears and in the proper identification of the causative Plasmodium species and quantification of the parasite load [1]. These centres usually rely on rapid diagnostic tests for the diagnosis of malaria. However, these tests do not provide any information about the severity of the infection, which is mandatory for evaluation of Plasmodium falciparum infections. Therefore, wellvalidated, simple, laboratory-based prognostic markers would be of great value in assisting clinicians dealing with returned travellers with malaria. Unfortunately, many laboratory markers including parasitaemia have poor sensitivity, specificity and predictive values for estimating the severity of disease [2].

Procalcitonin (PCT), a precursor peptide from the hormone calcitonin, has been considered by some, but not all, to be a specific and useful indicator of systemic bacterial infections $[3,4]$. Interestingly, elevated PCT levels (measured with quantitative assays), were also demonstrated in several patient series with malaria [5-11]. In the present study, the diagnostic accuracy of PCT for severe $P$. falciparum disease was evaluated in a cohort of 100 consecutive travellers with various imported malaria species. For this purpose, the PCT-Q ${ }^{\circledast}$ test was used, a semi-quantitative immunochromatographic "point-of-care" test, which, in contrast to quantitative PCT assays, allows a rapid measurement of PCT without a need for further technical equipment or support and can be easily incorporated in the initial clinical assessment of travellers who return home ill.

\section{Methods \\ Patient selection}

The Harbour Hospital is a 161-bed general hospital located in Rotterdam, the Netherlands. It also harbours the Institute of Tropical Diseases, which serves as a national referral centre for tropical diseases. All patients reported herein were consecutive travellers diagnosed with imported malaria, who were admitted to the Institute of Tropical Diseases of the Harbour Hospital in the period January 2004 to December 2007 and participated in the PCTTM (ProCalciTonin in Travel Medicine) observational survey. The PCTTM was an observational study that had the aim of evaluating the diagnostic accuracy of the semi-quantitative PCT- $\mathrm{Q}^{\otimes}$ test (see below) in the initial assessment of travellers who return home sick after a stay in the tropics or sub-tropics. Of each traveller demographic, clinical and laboratory data were collected including a blood sample on admission for PCT testing. Patients were classified as having severe or complicated $P$. falciparum malaria if they met pre-specified criteria for severe malaria $[2,12]$.

\section{Laboratory methods}

Routine examinations included red blood cell count, haematocrit, white blood cell count, platelet count, serum electrolytes, total bilirubin, serum creatinine, liver enzymes, blood glucose and plasma lactate. Blood smears (thin and thick films), were obtained from finger pricks and stained with Giemsa and parasite counts were performed. Malaria was diagnosed by QBC analysis, PfHRP2 screening and conventional microscopy with subsequent specification of the Plasmodium species (Plasmodium falciparum, Plasmodium vivax, Plasmodium ovale or Plasmodium malariae, respectively). In case of $P$. falciparum infections, parasite density was expressed as the number of $P$. falciparum trophozoites per 100 red cells in a thin film or the number of parasites per 100 white blood cells in a thick film. The parasite load was calculated from these figures using the actual number of white or red blood cells counted in the blood sample.

PCT was measured with the BRAHMS PCT- ${ }^{\bowtie}$ test (Brahms Diagnostics, Germany) according to the instructions of the manufacturer. PCT results were classified as follows: a negative result or a PCT $<0,5 \mathrm{ng} / \mathrm{ml}$ was classified as "normal"; a PCT of $0,5 \mathrm{ng} / \mathrm{ml}$ or a PCT between 0,5 $2,0 \mathrm{ng} / \mathrm{ml}$ was classified as "low"; a PCT of $2,0 \mathrm{ng} / \mathrm{ml}$ or a PCT between 2,0-10,0 was classified as "moderate"; a PCT of $10,0 \mathrm{ng} / \mathrm{ml}$ and above $10 \mathrm{ng} / \mathrm{ml}$ was classified as "high" as recommended [13].

\section{Statistical methods}

All values are presented as median (range). For comparison between groups, the Mann-Whitney U test, KruskalWallis test or Chi square test were used as appropriate. Post-hoc analysis was performed using Mann-Whitney U test. P values at $\alpha<0.05$ were considered statistically significant.

\section{Results}

One hundred patients with imported malaria were included in this study. Twenty-nine travellers acquired a non- $P$. falciparum malaria infection $(P$. vivax $\mathrm{n}=23 ; P$. ovale $\mathrm{n}=4 ; P$. malariae $\mathrm{n}=2$ ), 65 travellers had an uncomplicated $P$. falciparum infection, whereas another six patients had severe $P$. falciparum disease. Thirty-one patients with uncomplicated $P$. falciparum disease, one patient with severe $P$. falciparum disease and eight patients with non- $P$. falciparum disease were considered to be semi-immune or partially immune, respectively. As depicted in Table 1, patients with a severe P. falciparum infection had the highest serum CRP, lactate, creatinine, lactate dehydrogenase and bilirubin concentrations and the lowest haemoglobin concentrations and platelet counts on admission. As shown in Table 2, the median PCT concentrations differed significantly between the three groups (Chi-square 17.8; $\mathrm{P}<0.001$ ). The lowest median PCT concentration was observed in the group of patients with non-severe $P$. falciparum infections, whereas patients with severe $P$. falciparum infections had the highest median PCT concentration (Table 2). 
Table I: General characteristics and laboratory findings on admission of 100 consecutive travellers with imported malaria, subdivided by causative Plasmodium species and disease severity.

\begin{tabular}{|c|c|c|c|c|}
\hline & $\begin{array}{l}\text { Non-P. falciparum malaria } \\
\qquad(n=29)\end{array}$ & $\begin{array}{l}\text { Uncomplicated } P \text {. falciparum } \\
\text { malaria } \\
(n=65)\end{array}$ & $\begin{array}{l}\text { Severe } P \text {. falciparum malaria } \\
\qquad(n=6)\end{array}$ & $P$ value \\
\hline Male/female & $22 / 7$ & $47 / 18$ & $4 / 2$ & 0,8790 \\
\hline Age (year) & $36(15-62)$ & $36(9-67)$ & $48(29-55)$ & 0,2077 \\
\hline \multicolumn{5}{|l|}{ Continent of acquisition } \\
\hline Africa & 11 & 62 & 5 & \\
\hline Asia & 11 & 2 & - & \\
\hline South America & 6 & - & I & \\
\hline $\begin{array}{l}\text { Parasite load } \\
\text { (trophozoites per uL) }\end{array}$ & - & $3422(23-385000)$ & $174900(80500-567000)$ & 0,0002 \\
\hline Plasma lactate (mmol/L) & $1,3(0,7-2,2) *$ & $1,5(0,9-4,4) *$ & $2,7(1,8-5,8)$ & 0,0083 \\
\hline $\mathrm{ESR}(\mathrm{mm} / \mathrm{h})$ & $19(3-82)$ & $16(1-73)$ & $17(11-54)$ & 0,1400 \\
\hline Haemoglobin (mmol/L) & $8,0(4,6-10,1)$ & $8,7(5,2-11,1)^{\circ}$ & $7,4(4,0-10,2)$ & 0,0297 \\
\hline Leucocytes $(\times 109 / \mathrm{L})$ & $4,7(1,9-9,3)$ & $4,9(1,8-9,0)$ & $6,6(3,2-18,5)$ & 0,3867 \\
\hline Platelets $(\times 109 / \mathrm{L})$ & $95(28-167) *$ & $80(11-247) *$ & $22(3-36)$ & 0,0010 \\
\hline C-reactive protein (mg/L) & $84(18-208) *$ & $109(5-280) \#$ & $175(15 \mid-265)$ & 0,0056 \\
\hline Plasma glucose (mmol/L) & $6,6(4,9-8,2)$ & $6,8(4,1-14,9)$ & $5,9(4,5-7,6)$ & 0,3100 \\
\hline Serum creatinine (umol/L) & $91(62-223) *$ & $95(56-208) *$ & $153(112-199)$ & 0,0028 \\
\hline Serum LDH (U/L) & $474(278-1133) *$ & $554(238-1234) *$ & $1272(787-2216)$ & 0,0011 \\
\hline Serum total bilirubin (umol/L) & $24(10-84) *$ & $26(4-164) *$ & $65(39-269)$ & 0,0033 \\
\hline
\end{tabular}

$* P<0.01$, compared with severe $P$. falciparum malaria

${ }^{\circ} \mathrm{P}<0.05$, compared with non- $P$. falciparum malaria

$\# \mathrm{P}<0.05$, compared with severe $P$. falciparum malaria

When the groups of patients with $P$. falciparum infections were combined and analysed together, a significant correlation between parasitaemia and PCT concentrations was observed. Patients with a high PCT concentration had a significantly higher parasitaemia compared with patients who had a low or moderate PCT concentration (Figure 1). Interestingly, in all patients with severe $P$. falciparum malaria the elevated PCT levels on admission were classified as moderate $(n=2)$ or high $(n=4)$, respectively. Depending on the selected cut-off point (Table 3), PCT had an excellent sensitivity for severe $P$. falciparum disease, whereas specificity was poor. At a cut-off point of $10 \mathrm{ng} /$ $\mathrm{mL}$, the test characteristics became clinically relevant with a sensitivity of 0,67 and a specificity of 0,94 for severe $P$. falciparum disease.

Table 2: Procalcitonin (PCT) levels on admission in relation to causative Plasmodium species.

\begin{tabular}{lcccc}
\hline PCT & Non-P. falciparum malaria & Uncomplicated $P$. falciparum malaria & Severe $P$. falciparum malaria \\
\hline Normal & 4 & 23 & 0 & 27 \\
Low & 5 & 16 & 21 \\
Moderate & 14 & 22 & 2 & 0 \\
High & 6 & 4 & 4 & 14 \\
& 29 & 65 & 6 & 100
\end{tabular}

Non- $P$. falciparum vs uncomplicated $P$. falciparum $p=0.004$

Non- $P$. falciparum vs severe $P$. falciparum $P=0.031$

Uncomplicated $P$. falciparum vs severe $P$. falciparum $p<0.001$

\section{Discussion}

In this study, a semi-quantitative PCT test was evaluated as a diagnostic tool for severe $P$. falciparum disease because this 'point-of-care' test may be easily incorporated in the initial clinical assessment of travellers who return home ill, without a need for further technical equipment or support. To that end, PCT levels on admission were studied in a broad spectrum of manifestations of imported malaria, ranging from uncomplicated to severe $P$. falciparum malaria, as well as in non-falciparum malaria. Interestingly, in all patients with severe $P$. falciparum disease a moderate to high level of PCT was seen on admission, which agrees with observations made by others $[6,8]$. Some authors even suggested that an elevated PCT has prognostic value based on observations that PCT levels > $25 \mathrm{ng} / \mathrm{mL}$ were related to a fatal outcome in six of seven 


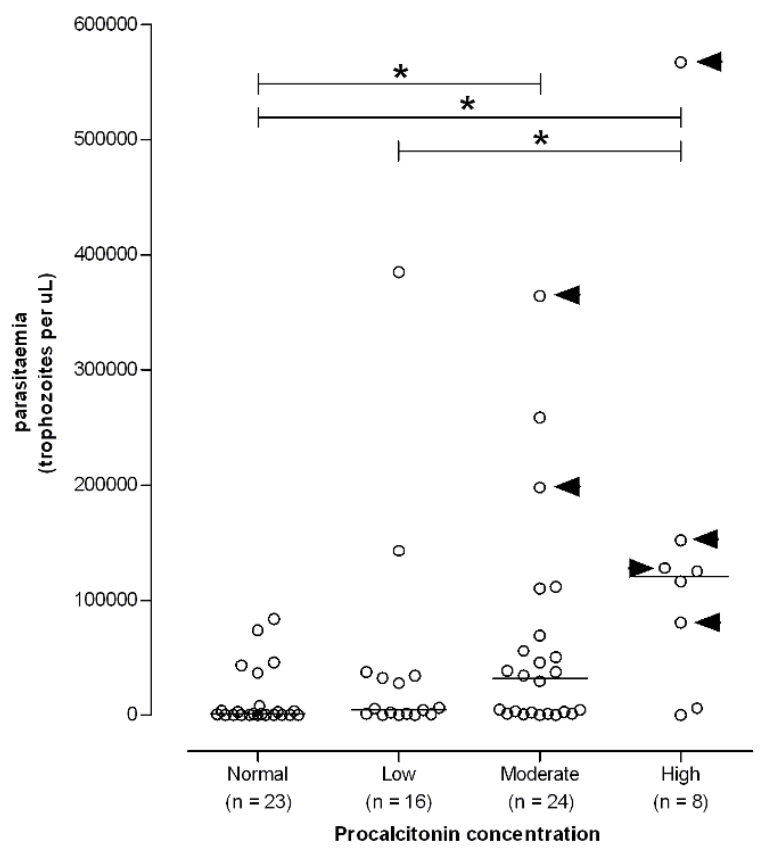

Figure I

Procalcitonin (PCT) levels on admission in relation to parasite load in $7 \mathrm{I}$ patients with falciparum malaria. Bars represent the median value of each group. Arrow heads indicate the patients with severe falciparum malaria. Statistical analysis showed an overall statistically significant difference between the various PCT groups on admission ( $p=0.0012$ ). Post-hoc group-to-group analysis showed significant differences in parasite load (identified by the asterix sign *) between various PCT groups (Normal vs moderate, $p=0.0044$; normal vs high, $p=0.0013$; and low vs high, $p=0.0403$, respectively).

patients with severe P. falciparum disease [6]. However, these assumptions were not validated in some other studies where PCT levels on admission were even higher (up to $662 \mathrm{ng} / \mathrm{mL}$ ) but without associated case-fatalities [8].
Interestingly, although severe or fatal malaria rarely results from infections with the non-sequestering Plasmodium species, $P$. vivax, $P$. ovale and $P$. malariae, increased PCT levels were observed in the majority of these patients on admission as well. Although speculative, these findings may imply that the mechanism whereby PCT levels increase in severe $P$. falciparum disease do not accurately reflect pivotal pathophysiological events in complicated $P$. falciparum disease, like sequestration of infected red blood cells in the microcirculation of vital organs. Rather, the elevation of PCT may be the result of activation of a common host response to malaria parasites. In fact, some even suggest that $P$. falciparum malaria per se is not associated with a stronger host response than $P$. vivax or $P$. ovale malaria, but that the density of the infection of the causative Plasmodium species influences the extent of the host response [14].

In the present study, PCT had an acceptable to excellent sensitivity for severe $P$. falciparum disease and a high negative predictive value. Given the low percentage of false negatives (i.e. patients with a low PCT on admission who nonetheless experienced a complicated course of malaria), the use of semi-quantitative PCT levels on admission to guide to treatment, would result in only very few patients with severe $P$. falciparum malaria being denied high-level monitoring and intensive treatment. However, the specificity and positive predictive value of the semi-quantive PCT test were rather poor. Applying semi-quantitative PCT levels on admission as a guide to therapy would therefore lead to a large proportion of patients receiving more intensive monitoring and treatment than strictly necessary. In our opinion, only at a PCT cut-off point of $10 \mathrm{ng} / \mathrm{mL}$ for severe P. falciparum disease, the test characteristics were clinically valuable. Moreover, in settings were the prevalence of malaria is lower than that reported herein, the positive predictive value of PCT will probably be even lower resulting in more false positive tests.

Table 3: Descriptive statistics of the accuracy of procalcitonin (PCT) as a diagnostic tool for severe Plasmodium falciparum disease using various cut-off points.

\begin{tabular}{|c|c|c|c|}
\hline \multirow[b]{2}{*}{ P. falciparum species only $(n=7 \mathrm{I})$} & \multicolumn{3}{|c|}{ PCT cut-off point } \\
\hline & $0,5 \mathrm{ng} / \mathrm{ml}$ & $2,0 \mathrm{ng} / \mathrm{mL}$ & $10,0 \mathrm{ng} / \mathrm{mL}$ \\
\hline Sensitivity & I,00 [n.a.] & I,00 [n.a.] & $0,67[0,56-0,78]$ \\
\hline Specificity & $0,35[0,24-0,46]$ & $0,60[0,49-0,7 I]$ & $0,94[0,88-1,00]$ \\
\hline Positive predictive value & $0,13[0,05-0,21]$ & $0,19[0,10-0,28]$ & $0,50[0,38-0,62]$ \\
\hline Negative predictive value & $\mathrm{I}, 00$ [n.a.] & $\mathrm{I}, 00$ [n.a.] & $0,97[0,93-1,00]$ \\
\hline All plasmodium species $(\mathrm{n}=100)$ & $0,5 \mathrm{ng} / \mathrm{ml}$ & $2,0 \mathrm{ng} / \mathrm{mL}$ & $10,0 \mathrm{ng} / \mathrm{mL}$ \\
\hline Sensitivity & 1,00 [n.a.] & 1,00 [n.a.] & $0,67[0,58-0,76]$ \\
\hline Specificity & $0,29[0,20-0,38]$ & $0,5 \mid[0,4|-0,6|]$ & $0,94[0,83-0,95]$ \\
\hline Positive predictive value & $0,08[0,03-0,13]$ & $0,19[0,06-0,18]$ & $0,50[0,20-0,38]$ \\
\hline Negative predictive value & $\mathrm{I}, 00$ [n.a.] & I,00 [n.a.] & $0,97[0,95-1,00]$ \\
\hline
\end{tabular}

Data is shown as proportion [95\% confidence interval]. 
Possibly, the overall sensitivity of PCT for the prediction of the course of malaria, could be improved if PCT was measured more precisely by use of an ultrasensitive PCT assay instead of the semi-quantitative assay used in this study. Several studies have directly compared the performance of both techniques and demonstrated satisfactory but not complete, concordance $[13,15]$. However, in the latter study [15], a satisfactory concordance was only reached when results in the next category were included to account for readout errors, which may further compromise the applicability of this semi-quantitative test in clinical practice.

Another drawback on the use of PCT for estimating malaria severity might be the occurrence of bacterial coinfection, which may also lead to elevated PCT levels on admission. In a large French intensive care unit study on imported severe falciparum malaria, 13 of 93 (14\%) patients with severe imported malaria were diagnosed with a concomitant bacterial infection, which contributed to a poor outcome [16]. However, in this study, blood cultures were routinely taken on admission in case of fever and remained negative, making the occurrence of concomitant bacteraemia a less likely event.

\section{Conclusion}

Severe P. falciparum disease and non-falciparum malaria are associated with elevated PCT levels on admission. Although determination of PCT may be of some help in the initial clinical assessment of disease severity in travellers with falciparum malaria in hospitals with extensive experience with the treatment of malaria, the overall test characteristics were too poor to advocate a general use of this semi-quantitative PCT assay. Potential drawbacks in the interpretation of elevated PCT levels on admission may be caused by infections with non-falciparum Plasmodium species and by concomitant bacterial infections.

\section{Competing interests}

The authors declare that they have no competing interests.

\section{Authors' contributions}

DAH participated in the data collection, performed the statistical analysis and data interpretation and contributed to the writing of the manuscript. JSB and HBT participated in the data collection and contributed to the writing of the manuscript. PP performed the procalcitonin assays, undertook the data collection and contributed to the manuscript. PVG conceived and designed the study, carried out the main analysis and wrote the manuscript. All authors approved the final version of the manuscript.

\section{Acknowledgements}

The authors gratefully acknowledge the help of Mr. Rob Koelewijn in collection of the patient data and samples for laboratory analysis and Ms. Corine Stuij for expert secretarial assistance.

\section{References}

I. Hänscheid T: Current strategies to avoid misdiagnosis of malaria. Clin Microbiol Infect 2003, 9:497-504.

2. World Health Organization: Severe malaria. Trans $R$ Soc Trop Med Hyg 2000, 94(Suppl I): I-90.

3. Muñoz P, Simarro N, Rivera M, Alonso R, Alcalá L, Bouza E: Evaluation of procalcitonin as a marker of infection in a nonselected sample of febrile hospitalized patients. Diagn Microbiol Infect Dis 2004, 49:237-24I.

4. Jones AE, Flechtl JF, Brown MD, Ballew JJ, Kline JA: Procalcitonin test in the diagnosis of bacteremia: a meta-analysis. Ann Emerg Med 2007, 50:34-4I.

5. Al-Nawas B, Shah PM: Procalcitonin in acute malaria. Eur J Med Res 1997, 2:206-208.

6. Chiwakata CB, Manegold C, Bonicke L, Waase I, Julch C, Dietrich M: Procalcitonin as a parameter of disease severity and risk of mortality in patients with Plasmodium falciparum malaria. $J$ Infect Dis 2001, 183:1 161-1164.

7. Davis TM, Assicot M, Bohuon C, St John A, Li GQ, Anh TK: Serum procalcitonin concentrations in acute malaria. Trans $R$ Trop Med Hyg 1994, 88:670-67I.

8. Hollenstein U, Looareesuwan S, Aichelburg A: Serum procalcitonin levels in severe Plasmodium falciparum malaria. $\mathrm{Am} J$ Trop Med Hyg 1998, 59:860-863.

9. Manegold C, Schmiedel S, Chiwakata CB, Dietrich M: Procalcitonin serum levels in tertian malaria. Malar J 2003, 2:34.

10. Richard-Lenoble D, Duong TH, Ferrer A: Changes in procalcitonin and interleukin 6 levels among treated African patients with different clinical forms of malaria. Trans $R$ Soc Trop Med Hyg 1997, 9 I:305-306.

II. Uzzan B, Izri A, Durand R, Deniau M, Bouchaud O, Perret GY: Serum procalcitonin in uncomplicated falciparum malaria: a preliminary study. Travel Med Infect Dis 2006, 4:77-80.

12. van Genderen PJ, Meer I van de, Consten J, Petit PL, van Gool T, Overbosch D: Evaluation of plasma lactate as a parameter for disease severity on admission in travelers with Plasmodium falciparum malaria. J Travel Med 2005, I 2:26I-264.

13. Meisner M, Brunkhorst FM, Reith HB, Schmidt J, Lestin HG, Reinhart $\mathrm{K}$ : Clinical experience with a new semi-quantitative solid phase immunoassay for rapid measurement of procalcitonin. Clin Chem Lab Med 2000, 38:989-995.

14. Hemmer CJ, Holst FG, Kern P, Chiwakata CB, Dietrich M, Reisinger EC: Stronger host response per parasitized erythrocyte in Plasmodium vivax or ovale than in Plasmodium falciparum malaria. Trop Med Int Health 2006, I I:817-823.

15. Kordek A, Podraza W, Czajka R: Reliability of semi-quantitative determination of procalcitonin serum concentrations in neonates. Diagn Microbiol Infect Dis 2006, 6:3I-34.

16. Bruneel F, Hocqueloux L, Alberti C, Wolff M, Chevret S, Bedos JP, Durand R, Le Bras J, Regnier B, Vachon F: The clinical spectrum of severe imported falciparum malaria in the intensive care unit. Am J Respir Crit Care Med 2003, 167:684-689.

Publish with Bio Med Central and every scientist can read your work free of charge

"BioMed Central will be the most significant development for disseminating the results of biomedical research in our lifetime. "

Sir Paul Nurse, Cancer Research UK

Your research papers will be:

- available free of charge to the entire biomedical community

- peer reviewed and published immediately upon acceptance

- cited in PubMed and archived on PubMed Central

- yours - you keep the copyright

Submit your manuscript here:

http://www.biomedcentral.com/info/publishing_adv.asp
BioMedcentral 